\begin{tabular}{l|l} 
2. To: (Receiving organizations & 3. From: corigina \\
Remote System and Sensor & Remote Syst \\
Applications, 8A800 & Application \\
5. Proj./Prog./0ept./Oiv.: & 6. Cog. Engr.: \\
LDUA & D.A. Clark \\
\hline
\end{tabular}

8. Originator Remarks:

Initial release of Operation and Maintenance Manual for the LDUA At-Tank Instrument Enclosure (System 4300)

ETN -96-0007
4. Related EDT No.:

None

7. Purchase Order No.:

N/A

9. Equip./Component No.:

LDUA/4300

10. System/Bldg./Facility:

$$
\mathrm{N} / \mathrm{A}
$$

12. Major Assm. Dwg. No,: $N / A$

13. Permit/Permit Application No.: $N / A$

14. Required Response Date: $N / A$

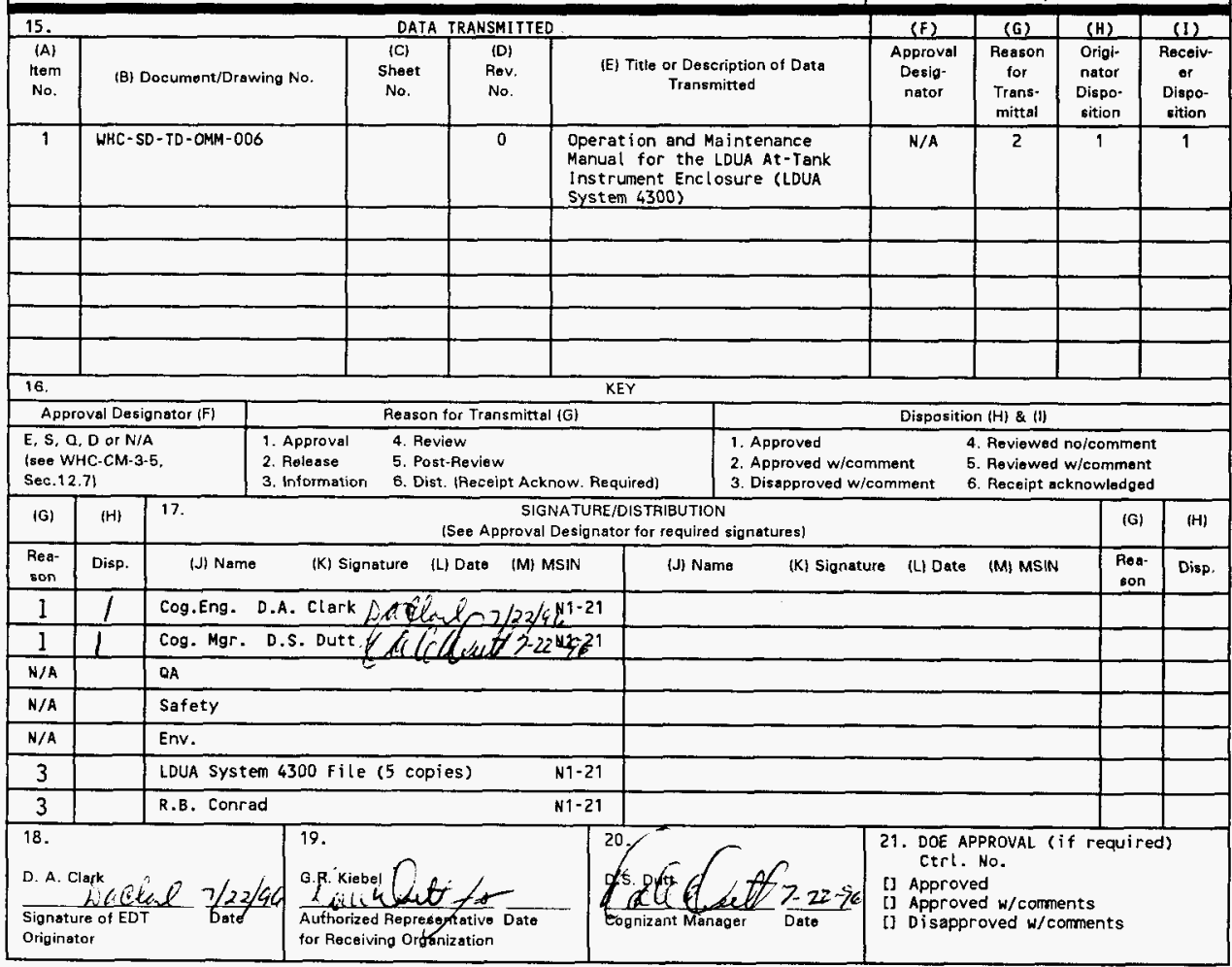

BD-7400-172-2(04/94) GEF097 


\section{Operation and Maintenance Manual for the LDUA At-Tank Instrument Enclosure (LDUA System 4300)}

\section{D.A. Clark}

Westinghouse Hanford Company, Richland, WA 99352

U.S. Department of Energy Contract DE-ACO6-87RL10930

\begin{tabular}{|c|c|c|}
\hline $\begin{array}{l}\text { EDT/ECN: } \\
\text { Org Code: } \\
\text { B\&R Code: }\end{array}$ & $\begin{array}{l}612371 \\
8 A 800 \\
\text { EW4010000 }\end{array}$ & $\begin{array}{l}\text { UC: } 2060 \\
\text { Charge Code: } \\
\text { Total Pages: }\end{array}$ \\
\hline
\end{tabular}

Key Words: Light Duty Utility Arm (LDUA), At-Tank Instrument Enclosure (ATIE), Operation, Maintenance, Procedure, Manual

Abstract: The Light Duty Utility Arm (LDUA) At-Tank Instrument Enclosure has completed testing and is ready for operation. This document defines the requirements applicable to the operation and maintenance of the At-Tank Instrument Enclosure.

TRADEMARK DISCLAIMER. Reference herein to any specific commercial product, process, or service by trade name, trademark, manufacturer, or otherwise, does not necessarjly constitute or jmply its endorsement, recommendation, or favoring by the United States Government or any agency thereof or its contractors or subcontractors.

Printed in the United States of America. To obtain copies of this document, contact: WHC/BCS Document Control Services, P.O. Box 1970, Mailstop H6-08, Richland WA 99352, Phone (509) 372-2420; Fax (509) 376-4989.
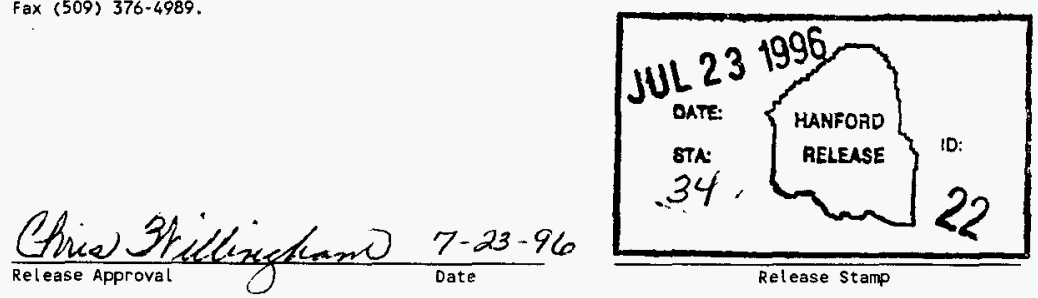

\section{Approved for Public Release}




\title{
OPERATION AND MAINTENANCE MANUAL
}

$$
\text { for }
$$

The LDUA At-Tank Instrument Enclosure

(LDUA System 4300)

July 15, 1996

by

\author{
D. A. CLARK
}

Remote System and Sensor Applications

Westinghouse Hanford Company

Richland, Washington 


\section{TABLE OF CONTENTS}

\section{OPERATION AND MAINTENANCE MANUAL}

FOR THE LDUA AT-TANK INSTRUMENT ENCLOSURE (SYSTEM 4300)

1.0 GENERAL EQUIPMENT INFORMATION $\ldots \ldots \ldots \ldots \ldots \ldots \ldots \ldots \ldots$

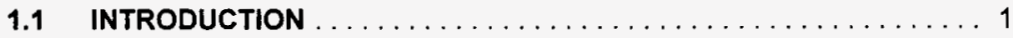

1.2 EQUIPMENT DESCRIPTION $\ldots \ldots \ldots \ldots \ldots \ldots \ldots \ldots \ldots$

1.3 REFERENCE DOCUMENTS $\ldots \ldots \ldots \ldots \ldots \ldots \ldots \ldots \ldots$

2.0 SPECIAL REQUIREMENTS $\ldots \ldots \ldots \ldots \ldots \ldots \ldots \ldots \ldots \ldots \ldots$

2.1 UTILITIES REQUIRED $\ldots \ldots \ldots \ldots \ldots \ldots \ldots \ldots \ldots \ldots \ldots$

2.2 SPECIAL TOOLS AND EQUIPMENT $\ldots \ldots \ldots \ldots \ldots \ldots \ldots$

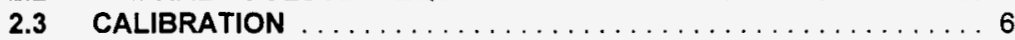

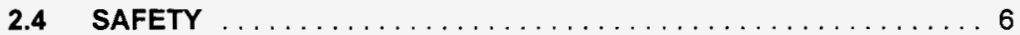

3.0 OPERATION PROCEDURE $\ldots \ldots \ldots \ldots \ldots \ldots \ldots \ldots \ldots \ldots \ldots \ldots$

3.1 SETUP \& OPERATION $\ldots \ldots \ldots \ldots \ldots \ldots \ldots \ldots \ldots \ldots \ldots$

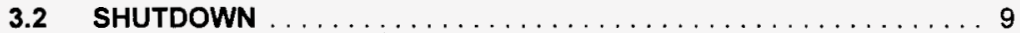

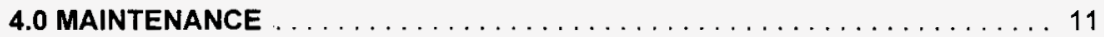

4.1 SCHEDULED MAINTENANCE $\ldots \ldots \ldots \ldots \ldots \ldots \ldots \ldots \ldots \ldots$

4.2 CORRECTIVE MAINTENANCE $\ldots \ldots \ldots \ldots \ldots \ldots \ldots \ldots \ldots 11$

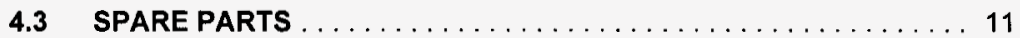

4.4 MAINTENANCE RECORDS $\ldots \ldots \ldots \ldots \ldots \ldots \ldots \ldots \ldots \ldots$

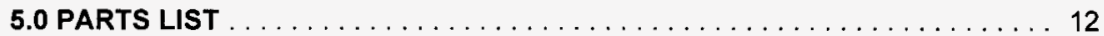

Figure 1

ATIE External Layout $\ldots \ldots \ldots \ldots \ldots \ldots \ldots \ldots \ldots \ldots \ldots \ldots$

Figure 2

ATIE Internal Layout (Front View) $\ldots \ldots \ldots \ldots \ldots \ldots \ldots \ldots \ldots$

Figure 3

Overtemperature Switch Location $\ldots \ldots \ldots \ldots \ldots \ldots \ldots \ldots \ldots$

Figure 4

Air Conditioner Thermostat Location $\ldots \ldots \ldots \ldots \ldots \ldots \ldots \ldots \ldots$ 


\section{OPERATION AND MAINTENANCE MANUAL FOR THE LDUA AT-TANK INSTRUMENT ENCLOSURE (SYSTEM 4300)}

\subsection{GENERAL EQUIPMENT INFORMATION}

This document contains the instructions for operation and maintenance of the Light Duty Utility Arm (LDUA) At-Tank Instrument Enclosure (ATIE), LDUA subsystem number 4300.

\subsection{INTRODUCTION}

The ATIE consists of a weatherproof (NEMA-4) instrument enclosure with heating and air conditioning; internal power distribution circuits for providing $120 \mathrm{VAC}$ power to installed instrumentation; and miscellaneous instrument cabling as required to support interfacing between at-tank portions of the LDUA system. The primary purpose of the ATIE is to house and protect LDUA system instrumentation which must be located near the tank where the system is deployed. A secondary purpose is to provide a convenient power connection point for in-tank hardware that is not mounted on the LDUA itself (i.e., Overview Video System, Overview Stereo Video System, Topographical Mapping System). Sketches of the ATIE layout are included as Figures 1 and 2.

\subsection{EQUIPMENT DESCRIPTION}

\subsubsection{General Description}

The design of the ATIE is based on an Electrorack three-bay, NEMA-4 weathertight instrument enclosure with an external air conditioner. An HVAC system is installed to maintain the internal temperature within acceptable limits for standard instrumentation over the exterior temperature range specified in the LDUA Functions and Requirements. The cabinet is fully insulated and sunshields are installed to reduce the heat load on the HVAC system. Internal lighting is provided in each bay of the enclosure. Insulation, ductwork, sunshields, heaters, lighting, and the internal power distribution system were designed by Los Alamos Technical Associates (LATA) of Richland, Washington, with fabrication by H\&N Electric of Pasco, Washington.

Each instrument bay is designed to accept standard 19-inch rack-mountable instruments. The vertical mounting bracket spacing is 30.25 inches. The maximum depth of each instrument, including connectors/cables protruding from the rear of the instrument, is 34.5 inches. All instruments must have flat front faces (no protruding handles or controls) to prevent interference with the enclosure doors. The instrument bays are open on the sides to simplify cable routing and permit free flow of cooling air. 


\subsubsection{Power and Control Description}

Power is supplied to the ATIE by two feeds from the Power Distribution Skid (LDUA subsystem 5130). A 208 VAC, single-phase feed provides power to the air conditioner unit mounted on the enclosure side. Power to the air conditioner may be isolated via a disconnect switch mounted above the air conditioner housing. Instrument, heating, and lighting power are provided via a 208Y/120 VAC feed that comes into a distribution breaker enclosure inside the right-hand instrument bay (subassembly 4300A3). Each instrument bay is equipped with a heater, dooroperated lights, and two $120-\mathrm{VAC}, 20 \mathrm{amp}$ power strips for rack-mounted instruments.

An overtemperature trip switch is mounted in the top of the left-hand instrument bay (subassembly 4300A1, see Figure 3 ). The switch will de-energize all internal loads by tripping the instrument power input breaker if the ATIE internal temperature exceeds the setpoint. This feature protects the internal instruments against overheating due to an air conditioner failure.

\subsubsection{HVAC Description}

Cooling is provided by an externally mounted 22,000 btu Kooltronic air conditioner. An air-to-air heat exchanger in the air conditioner allows recirculation of the interior air so that no communication with the outside air is necessary. The air conditioner thermostat is mounted behind the inlet filter (see Figure 4), with the sensing element located on the ATIE interior wall. The cold air outlet of the air conditioner is ducted to each of the instrument bays. Adjustable louvers are provided in each bay to permit control of the air flow. The air conditioner fan blows whenever the air conditioner is powered to provide air circulation even when the unit is not cooling.

Each instrument bay is equipped with a floor-mounted 400 watt resistance heater. The heaters have individual thermostats and internal circulation fans. An interlock prevents operation of any heater if the air conditioner compressor is running.

\subsubsection{Instrumentation}

There are two categories of instruments installed in the ATIE; permanent and end effector (EE). Permanent instrumentation is used to support LDUA operations during all campaigns (a campaign is a deployment cycle, from setup to removal, at a particular waste tank), while $E E$ instrumentation may change between campaigns depending on the end effectors (tools mounted on the end of the LDUA) that will be used during a particular campaign. 


\subsubsection{Permanent Instrumentation}

The permanently installed instrumentation consists of the following equipment:

- Fiber-Optic Interface Panel (Subsystem 4300A1A1). Provides a termination panel for the fiber-optic umbilical cable running between the Operations Control Trailer (OCT) and the at-tank instrumentation.

- Video Fiber-Optic Converter (Subsystem 4220A1). Converts video signals from the end effector cameras for transmission over the fiber-optic umbilical cable.

- Network Fiber-Optic Converter (Subsystem 4400A4). Converts 10BaseT control network signals to fiber-optic for transmission over the fiber-optic umbilical cable.

- $\quad$ General I/O \#1 and \#2 (Subsystems 4220A2 and 4220A11). Controls for remote operation of end effectors and at-tank equipment.

- Radiation Monitor Electronics (Subsystem 3520A1). Signal conditioning modules for the radiation detectors mounted in the water decontamination system.

- ATIE Kit (Subsystem 2400A7). At-tank interface for control of the LDUA from the OCT.

Interconnection cabling for the above instruments, as well as connections to the ATIE exterior if needed, are documented in the ATIE drawings.

\subsubsection{End Effector Instrumentation}

End Effector instrumentation is expected to change dependent upon the requirements of each LDUA system campaign. The LDUA system design assumes the electronics needed for each campaign will be mounted in the ATIE at the beginning of the campaign. When end effectors are switched during the campaign, the interfacing ATIE cables are merely connected to the appropriate EE electronics package in the ATIE. There are a maximum of six connectors that have to be mated following EE changeout; not all end effectors will require use of all connectors. All connectors are quickdisconnect type for ease of operation. Details of the EE interfaces with the ATIE cabling can be found in WHC-SD-TD-CR-001, Design Criteria for the 
Light Duty Utility Arm System End Effectors. The ATIE connectors that mate with the EE electronics are:

\begin{tabular}{|l|l|}
\hline \multicolumn{1}{|c|}{ Cable Function } & Connector Number \\
\hline TIP Utility Power & 4300A2W1P1 \\
\hline $\begin{array}{l}\text { TIP Utility Signals 1-15 (also known as } \\
\text { Signal 1) }\end{array}$ & 4300A2W2P1 \\
\hline $\begin{array}{l}\text { TIP Utility Signals 16-30 (also known as } \\
\text { Signal 2) }\end{array}$ & 4300A2W3P1 \\
\hline TIP Utility 75-ohm coax & 4300A2W4P1 \\
\hline TIP Utility 50-ohm coax & 4300A2W4P2 \\
\hline Loss of purge pressure signal & 4300A2A1W6P1 \\
\hline
\end{tabular}

\subsubsection{Exterior Connections}

The ATIE serves as an interface point for several LDUA subsystems. External connections are provided for 120 VAC power, instrument, and pneumatic services. Details of the exterior connections are available on the ATIE drawings.

\subsection{REFERENCE DOCUMENTS}

The following reference documents provide additional information regarding the At-Tank Instrument Enclosure:

\subsubsection{Released Drawings}

H-6-14125, ATIE Assembly Drawing

H-6-14126, ATIE Elementary Diagram and Panelboard Schedule

H-6-12128, ATIE Opto-22 Drawer \#1 (4220A2)

H-6-14129, ATIE Interlock Junction Drawer (4300A1A2)

\subsubsection{Non-Released Drawings (available from LDUA system file 4300)}

H-6-14130, At-Tank Instrument Enclosure Equipment Arrangement

H-6-14131, At-Tank Instrument Enclosure (ATIE) Interconnection Diagram 
H-6-14132, ATIE Opto-22 Drawer No. 1 Wiring Diag

H-6-14133, ATIE Opto-22 Drawer No. 2 Wiring Diag

H-6-14134, ATIE Interlock Junction Drawer Wiring Diag

H-6-14135, At-Tank Instrument Enclosure (ATIE) Internal Cable Assy's

H-6-14145, LDUA System Misc Cable Assemblies

Sketch 4100W1-2.SKD, Fiber-Optic Umbilical

\subsubsection{Miscellaneous Documents}

WHC-SD-TD-TRP-003, Test Report for the Light Duty Utility Arm At-Tank Instrument Enclosure (ATIE)

WHC-SD-TD-FRD-003, Functions and Requirements for the Light Duty Utility Arm Integrated System

WHC-SD-WM-SEL-034, Preliminary Safety Equipment List for the Light Duty Utility Arm System

WHC-SD-TD-CR-001, Design Criteria for the Light Duty Utility Arm System End Effectors

NFPA 70-1993, National Electric Code

WHC-CM-1-10, Safety Manual 


\subsection{SPECIAL REQUIREMENTS}

\subsection{UTILITIES REQUIRED}

- 208Y/120 VAC, 3-phase, $60 \mathrm{~Hz}, 30$ amps/phase for internal instrument, heating, and lighting loads (fed from LDUA Power Distribution Skid, subsystem 5130)

- 208 VAC, single-phase, $60 \mathrm{~Hz}, 20$ amps for ATIE air conditioner (fed from LDUA Power Distribution Skid, subsystem 5130)

\subsection{SPECIAL TOOLS AND EQUIPMENT}

Handling: The fully-loaded ATIE weighs approximately $2500 \mathrm{lbs}$, and can be moved via crane or forklift.

Operation: No special tools are required for operation of the ATIE.

Maintenance: Standard electrician and instrument craft hand tools are required for maintenance. Work on energized components requires personnel protective equipment as specified in WHC-CM-1-10, Safety Manual.

\subsection{CALIBRATION}

There are no components in the ATIE requiring routine calibration.

\subsection{SAFETY}

The ATIE operates at voltages of 208 VAC single-phase and 208Y/120 VAC 3-phase. During normal operation, no energized parts are exposed. Special precautions are required only if corrective maintenance is needed.

The ATIE has been inspected for NEC compliance by the Hanford site electrical inspector.

\subsubsection{Personnel Precautions}

- Maintenance work shall be done using appropriate precautions specified in WHC-CM-1-10, Safety Manual. 
The LDUA system contains many pieces of remotely-operated equipment. Before beginning maintenance, all personnel working on the system shall be fully briefed regarding the scope of work and LDUA system status.

\subsubsection{Equipment Precautions}

None 


\subsection{OPERATION PROCEDURE}

\subsection{SETUP \& OPERATION}

\subsubsection{Prerequisites}

3.1.1.1 Moderately level (+/- 10 degree slope) area has been selected for ATIE placement.

3.1.1.2 Power Distribution System (PDS) and associated cables are in place, powered, and ready to provide power for the ATIE.

\subsubsection{Initial Setup}

\section{NOTE}

Use of the enclosure heaters and air conditioning is not required while the ATIE is in the Cold Test Facility (CTF) with one or more doors open. If desired, steps relating to air conditioner and heater operation may be omitted during CTF operation.

3.1.2.1 Using a crane or forklift, position ATIE at the deployment site. To minimize interior heating during summer operation, position the enclosure so the air conditioner end is facing approximately north

3.1.2.2 Position the air conditioner condensate drain to empty onto the ground.

3.1.2.3 Verify the air conditioner disconnect switch and all breakers on the 4300A3A1 power distribution panel are open.

3.1.2.4 Per the PDS operating procedure, verify all breakers on the PDS for supplying ATIE power are open.

3.1.2.5 Connect the air conditioner power cable connector 5100W4AP2 to connector 4300A4W1J1 on the ATIE exterior.

3.1.2.6 Connect the instrument power cable connector 5100W8AP2 to connector 4300A3W1J1 on the ATIE exterior. 


\subsubsection{Application of Power}

3.1.3.1 Set the air conditioner thermostat to approximately 80 degrees $F$. The thermostat is located behind the air conditioner inlet filter (see Figure 9) and can be accessed by temporarily removing the filter.

3.1.3.2 Verify the overtemperature switch TS-1 is set to approximately 100 degrees $F$.

3.1.3.3 Verify the thermostats on heaters HTR-1, HTR-2, and HTR-3 are set to approximately 65 degrees $F$.

3.1.3.4 Per the PDS operating procedure, provide power to the ATIE instrument and air conditioning circuits.

3.1.3.5 Close the air conditioner disconnect switch on the outside of the ATIE. The air conditioner circulation fans will start running (the compressor may also start if the ATIE interior temperature is above the setpoint).

3.1.3.6 Close all breakers on the ATIE internal power distribution panel 4300A3A1.

3.1.3.7 If the ATIE is set up outdoors, verify all doors are closed and protective covers are in place.

3.1.3.8 The ATIE is now operational and ready for use with the LDUA system.

\subsection{SHUTDOWN}

\subsubsection{Prerequisites}

3.2.1.1 All end-effector equipment installed in the ATIE and miscellaneous systems connected to the ATIE (decon, radiation monitoring, LDUA Mobile Deployment System) have been shut down per the appropriate equipment operating procedures.

\subsubsection{Power Distribution Shutdown}

3.2.2.1 On ATIE power distribution panel 4300A3A1, open all breakers.

3.2.2.2 Open the disconnect switch for the air conditioner (externally mounted). 
3.2.2.3 Per the PDS operating procedure, verify all breakers on the PDS for supplying ATIE power are open.

3.2.2.4 Disconnect power connectors 5100W4AP2 and 5100W8AP2 from the ATIE.

\subsubsection{Preparation For Transport}

3.2.3.1 Verify all LDUA equipment connected to the outside of the ATIE has been removed and protective covers over connecters or enclosure openings are installed.

3.2.3.2 Verify all internal ATIE equipment is properly secured.

3.2.3.3 Close and latch the enclosure doors.

3.2.3.4 The ATIE is now ready for transport. 


\subsection{MAINTENANCE}

\subsection{SCHEDULED MAINTENANCE}

- $\quad$ Before each deployment, inspect all cables for damage. Repair/replace damaged parts as necessary.

- At approximately 1-month intervals, inspect the air conditioner inlet filter. If dirty, the filter may be cleaned with water. Oily accumulations may be removed by washing in a mild detergent, followed by rinsing with water. Allow to dry thoroughly prior to re-installation. The filter may be coated with Kooltronic A-16 Filter Recoating Adhesive to trap fine airborne particulates.

- $\quad$ At approximately 1-year intervals, the ATIE should be inspected for cleanliness and all connections checked for satisfactory tightness.

- $\quad$ As required by WHC-CM-1-10, Safety Manual, the GFCI for the utility outlet on the ATIE shall be tested monthly, or before each use.

\subsection{CORRECTIVE MAINTENANCE}

Adherence to the scheduled maintenance requirements of section 4.1 will minimize the need for corrective maintenance. The drawings and vendor information contained in the LDUA file for system 4300 provide all information necessary to perform unscheduled corrective maintenance.

\subsection{SPARE PARTS}

There are no spare parts required for normal operation and maintenance of the ATIE.

\subsection{MAINTENANCE RECORDS}

A log shall be kept of all filter maintenance and tests of the GFCI for the ATIE utility outlet. The location of the log shall be determined by the TWRS operations and/or maintenance organization. 
WHC-SD-TD-OMM-006 Rev. 0

\subsection{PARTS LIST}

Refer to the ATIE drawings for a complete list of At-Tank Instrument Enclosure parts. Vendor information on these parts may be found in the LDUA file for system 4300 . 


\section{WHC-SD-TD-OMM-006 Rev. 0}

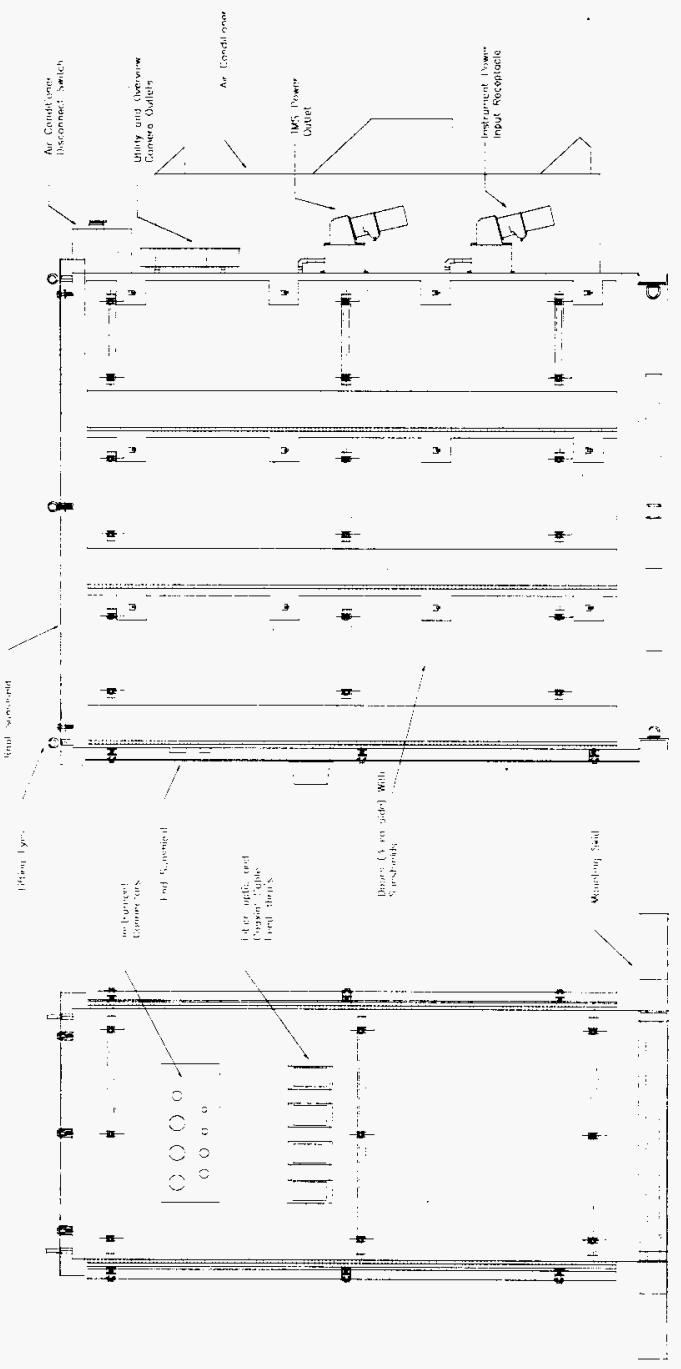

Figure 1

ATIE External Layout 
WHC-SD-TD-OMM-006 Rev. 0

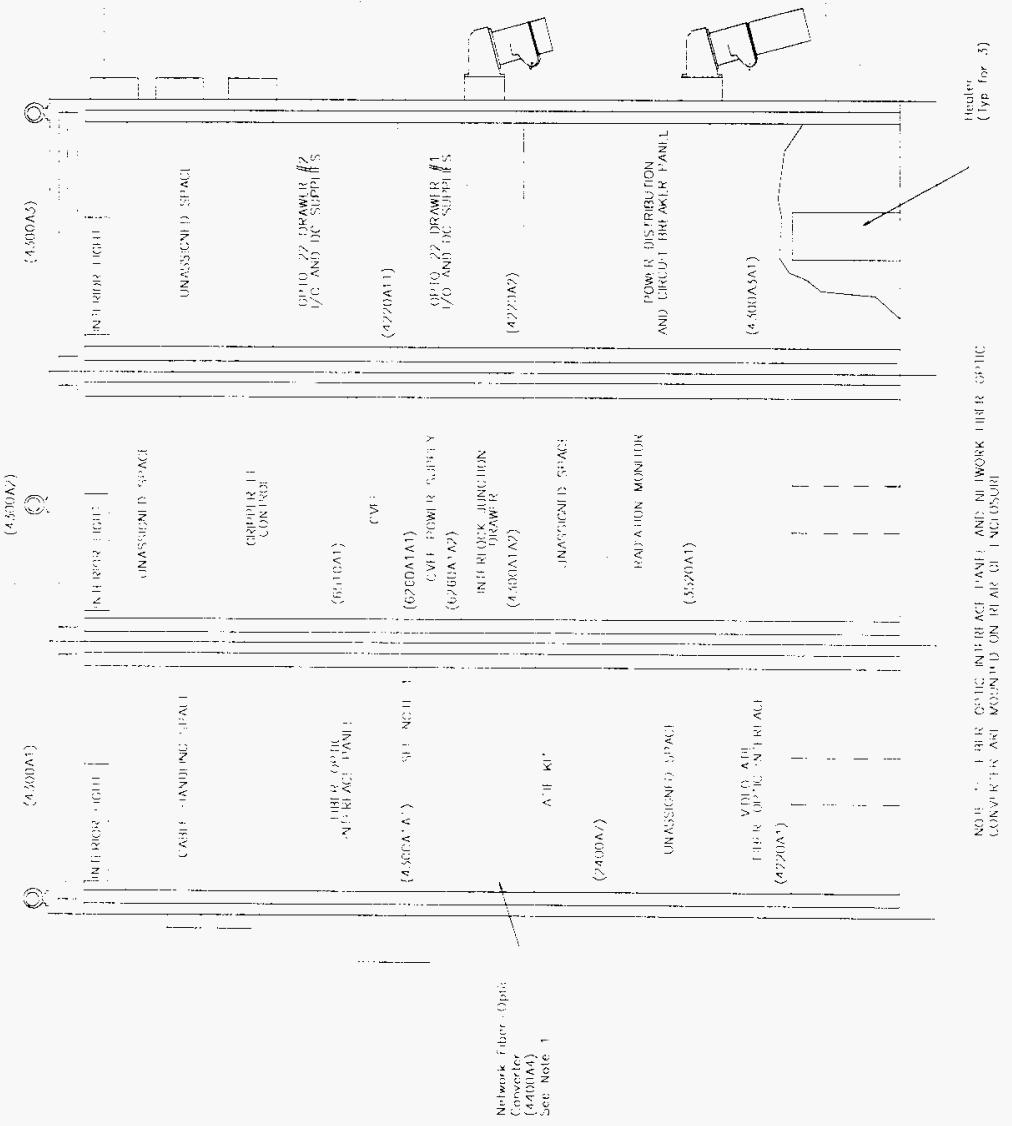

Figure 2

ATIE Internal Layout (Front View) 
WHC-SD-TD-OMM-006 Rev. 0

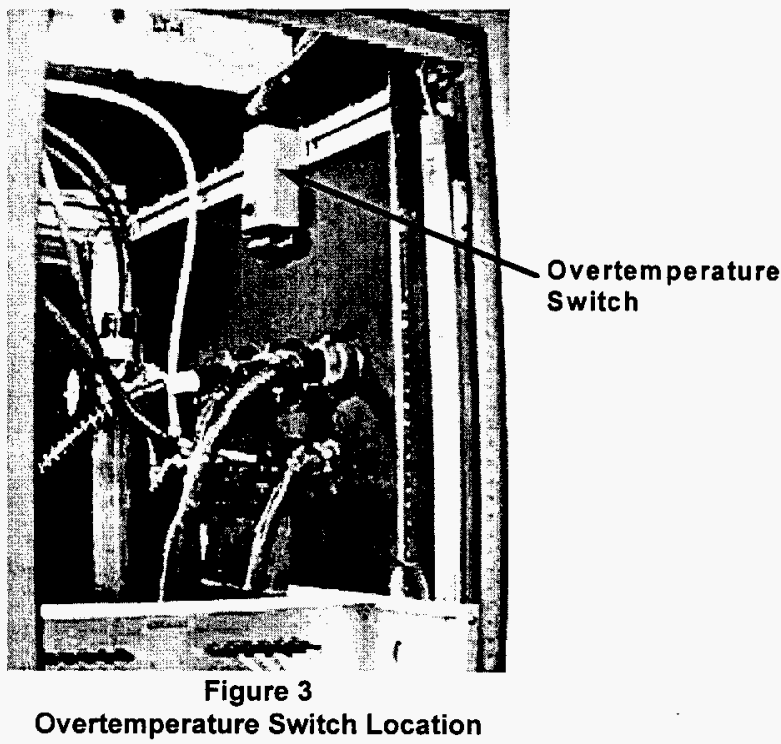




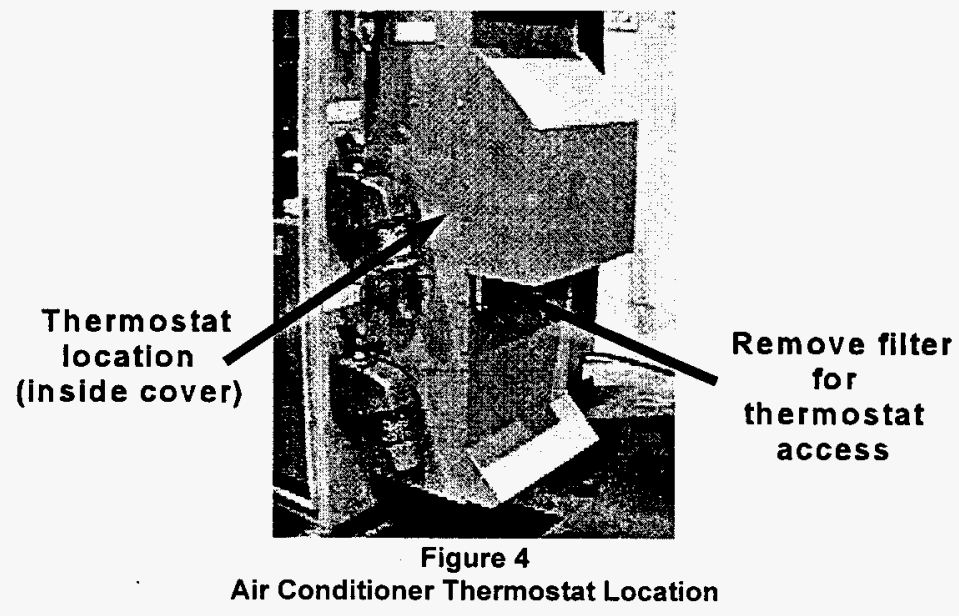

